\title{
A natural history comparison of SOD1-mutant patients with amyotrophic lateral sclerosis between Chinese and German populations
}

\author{
Lu Tang ${ }^{1,2 \dagger}$, Johannes Dorst ${ }^{3,4 \dagger}$, Lu Chen ${ }^{1,2}$, Xiaolu Liu' ${ }^{1,2}$, Yan Ma M $^{1,2}$, Kornelia Günther $^{3}$, Sebastian Michels ${ }^{3}$, \\ Kathrin Müller ${ }^{3}$, Axel Freischmidt ${ }^{3}$, Jochen H. Weishaupt ${ }^{3}$, Dongsheng Fan ${ }^{1,2^{*}}$ (I) and Albert C. Ludolph ${ }^{3,4^{*}}$
}

Currently, there is no effective treatment for amyotrophic lateral sclerosis (ALS), despite the limited efficacy of riluzole [1] and edaravone [2]. SOD1 (coding for the $\mathrm{Cu}$ / $\mathrm{Zn}$ superoxide dismutase) is the second most frequent genetic cause for ALS only after C9orf72 in patients with European ancestry while being the most frequent in Asian ALS populations [3]. Multiple therapeutic approaches have targeted SOD1-related ALS, including the antisense oligonucleotide tofersen with promising results in a recent phase I/II trial [4]. Given the clinical heterogeneity among different SOD1 mutations, in this study, we enrolled genetically confirmed ALS patients with SOD1 mutations from two prospectively established hospital-based cohorts from China [5] and Germany [6] to clinically characterize distinct SOD1 mutations and compare related phenotypes between Asians and Caucasians. Because of the explorative nature of this study, all results should be interpreted as hypothesis-generating only rather than confirmatory. No adjustment for multiple testing was made.

We identified 66 Chinese and 84 German ALS patients carrying a total of 69 distinct SOD1 mutations, including
61 known mutations of $S O D 1,5$ variants of uncertain significance, and 3 likely pathogenic variants. The most frequent mutation in both populations was p.His47Arg (8 Chinese and 2 German). All common mutations featured consistent phenotypes, including an aggressive form of ALS in p.Gly148Asp and slow-progressing forms in p.Glu41Gly, p.His47Arg and p.Asn87Ser (Additional file 1: Table S1). Interestingly, the majority of mutations in the Chinese patients were located in exon 2 while those in the German patients were in exon 4. There was a significant difference in the average age of onset between the Chinese and the German patients carrying mutations in exon 4 (37.4 vs 49.9 years, $P<0.001)$. The site of onset, diagnostic delay, and survival did not differ significantly among the exons (Additional file 1: Fig. S1).

Among all patients with SOD1 mutations, the median (Inter-Quartile Range [IQR]) age of onset was 46.0 (40.0-54.0) years and Chinese patients had younger age of onset (43.0 [38.3-50.0] vs 50.0 [41.0-58.0], $P=0.002$ ), which is consistent with a previous study [6]. However, the difference was not significant after adjusting for the demographic structures of the identical general ALS

*Correspondence: dsfan2010@aliyun.com; Albert.Ludolph@rku.de

†Lu Tang and Johannes Dorst have contributed equally to this work

${ }^{1}$ Department of Neurology, Peking University Third Hospital,

Beijing 100191, China

${ }^{3}$ Department of Neurology, Ulm University, 89081 Ulm, Germany

Full list of author information is available at the end of the article

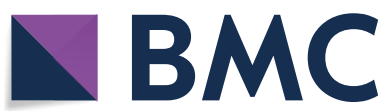

(c) The Author(s) 2021. Open Access This article is licensed under a Creative Commons Attribution 4.0 International License, which permits use, sharing, adaptation, distribution and reproduction in any medium or format, as long as you give appropriate credit to the original author(s) and the source, provide a link to the Creative Commons licence, and indicate if changes were made. The images or other third party material in this article are included in the article's Creative Commons licence, unless indicated otherwise in a credit line to the material. If material is not included in the article's Creative Commons licence and your intended use is not permitted by statutory regulation or exceeds the permitted use, you will need to obtain permission directly from the copyright holder. To view a copy of this licence, visit http://creativecommons.org/licenses/by/4.0/. The Creative Commons Public Domain Dedication waiver (http://creativeco mmons.org/publicdomain/zero/1.0/) applies to the data made available in this article, unless otherwise stated in a credit line to the data. 
populations [6] $(P=0.07)$. The proportion of youngonset ALS, defined as onset between 25 and 45 years, was $47.5 \%$ in the two cohorts, and was higher in China $(62.5 \%$ vs $30.7 \%, P<0.001$ ). The median (IQR) body mass index (BMI) at diagnosis was significantly lower in the Chinese cohort (22.6 [20.9-24.9]) than in the German cohort (25.9 [23.1-28.7], $P<0.001)$; this difference remained significant $(P=0.03)$ after adjusting for the BMI in the identical general ALS populations (median BMI: 23.0 in Chinese and 24.5 in German) [6].

The median (IQR) diagnostic delay was $12.0(6.0-35.0)$ months (Chinese: 14.5 [6.0-36.5] vs German: 11.0 [6.0$32.0], P=0.59)$, and the survival was $141.0(21.0-364.0)$ months (Chinese: not available due to $>60 \%$ censored cases; German: 198.0 [22.0-364.0]; $P=0.90$ ). Despite the lower riluzole prescription rate in the Chinese population (28.3\% vs $81.3 \%, P<0.001)$, no survival differences were observed $(P=0.90$, Table 1$)$.

The majority of cases $(94.3 \%)$ had spinal onset. There was no difference in the proportion of site of onset between two groups or between males and females. Twenty percent of patients had a pure lower motor neuron phenotype (Chinese: 17.3\%, German: $25.0 \%$, $P=0.41$; Table 1). Some of these patients progressed slowly (p.His47 Arg), while others showed an aggressive pattern (p.Ala5Val and p.His44Arg). Male patients had significantly shorter diagnostic delay $(P=0.01)$ and survival $(P=0.005)$ compared to females (Additional file 1 : Table S2, Fig. S2).
Because of the significant relationship between diagnostic delay and early and late progression rate (see definition in Additional file 2: Supplementary Methods), only sex, age of onset, site of onset, and late progression rate were included in the multivariate Cox regression analysis, which revealed that patients with bulbar onset (hazard risk 10.31, $P=0.01$ ) and higher late progression rate (hazard risk 2.42, $P=0.003$ ) had a much shorter survival time (Additional file 1: Table S3, Fig. S3).

The present study has three major implications. First, this study reported for the first time distinct distributions of SOD1 mutations in Chinese (mainly in exon 2) and German patients (mainly in exon 4), and consistent phenotypes in each of the common mutations. The most common SOD1 mutations in Germany were p.Arg116Gly (26 patients) and p.Asp91Ala (11), which could be explained by the known founder effects among Caucasian populations, and a similar effect may be involved in Chinese patients carrying p.His47Arg (8 patients). The predominate mutation in North America (p.Ala5Val) [7] was rare in China (only 1 patient), albeit without the same founder haplotype [8], and absent in Germany. Second, the Chinese SOD1-mutant patients had a significantly lower age of onset and higher proportion of young-onset cases compared with the German counterparts, which may reflect a higher burden of genetic and environmental risk factors [9]. Third, the known prognostic factors BMI and

Table 1 Clinical characteristics of Chinese and German ALS patients with SOD1 mutations

\begin{tabular}{|c|c|c|c|c|c|}
\hline & Total (data available) & China & Germany & $P$ & Adjusted $P^{a}$ \\
\hline \multicolumn{6}{|l|}{ Nominal variables, $n(\%)$} \\
\hline Numbers of subjects & 150 & 66 & 84 & & \\
\hline Sex, male & $80(55.6 \%)(144)$ & $35(53.8 \%)$ & $45(57.0 \%)$ & 0.70 & \\
\hline $\begin{array}{l}\text { Young-onset ALS } \\
\text { ( } 25-45 \text { years) }\end{array}$ & $63(47.5 \%)(139)$ & $40(62.5 \%)$ & $23(30.7 \%)$ & $<0.001$ & \\
\hline Site of onset, spinal & $116(94.3 \%)(123)$ & $57(91.9 \%)$ & $59(96.7 \%)$ & 0.25 & \\
\hline Pure LMN & $16(20.0 \%)(80)$ & $9(17.3 \%)$ & $7(25.0 \%)$ & 0.41 & \\
\hline Riluzole prescription & $54(53.5 \%)(101)$ & $15(28.3 \%)$ & $39(81.3 \%)$ & $<0.001$ & \\
\hline \multicolumn{6}{|c|}{ Continuous variables, median (IQR) } \\
\hline Age of onset (years) & $46.0(40.0-54.0)(139)$ & $43.0(38.3-50.0)$ & $50.0(41.0-58.0)$ & 0.002 & 0.07 \\
\hline BMl at diagnosis & $23.5(21.6-26.3)(91)$ & $22.6(20.9-24.9)$ & $25.9(23.1-28.7)$ & $<0.001$ & 0.03 \\
\hline Diagnostic delay (months) & $12.0(6.0-35.0)(107)$ & $14.5(6.0-36.5)$ & $11.0(6.0-32.0)$ & 0.59 & \\
\hline ALSFRS-R at diagnosis & $41.0(35.0-45.0)(116)$ & $42.0(35.5-46.0)$ & $40.0(31.0-44.0)$ & 0.04 & 0.70 \\
\hline Early progression rate & $0.42(0.14-0.90)(116)$ & $0.33(0.15-0.90)$ & $0.46(0.13-0.93)$ & 0.79 & 0.29 \\
\hline Late progression rate & $0.26(0.09-0.79)(69)$ & $0.28(0.08-0.80)$ & $0.17(0.11-0.77)$ & 0.89 & \\
\hline Survival (months) & $141.0(21.0-364.0)(140)$ & NA & $198.0(22.0-364.0)$ & 0.90 & \\
\hline Follow-up period & $24.0(7.3-40.8)(88)$ & $30.0(10.0-42.0)$ & $15.0(6.0-40.0)$ & 0.06 & \\
\hline
\end{tabular}

Bold $P$-values are significant as $P<0.05$

LMN, Lower motor neuron

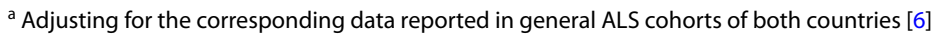


age of onset for sporadic ALS were not associated with survival in the $S O D 1$-carrying patients, indicating the different spectrum of disease-modifying factors.

In the future, it is desirable to establish a detailed genotype-phenotype database of SOD1 mutationcarriers in different populations in order to clarify the underlying pathomechanisms and to precisely design clinical trials for SOD1-related ALS.

\section{Abbreviations}

ALS: Amyotrophic lateral sclerosis; BMI: Body mass index; IQR: Interquartile ranges; SOD1: Superoxide dismutase-1.

\section{Supplementary Information}

The online version contains supplementary material available at https://doi. org/10.1186/s40035-021-00266-x.

Additional file 1. Table S1 Clinical characteristics of common mutations ( $\geq 2$ patients) in Chinese and German ALS patients. Table S2 Clinical comparison of patients carrying SOD 1 mutation by sex. Table S3 Cox regression analysis of SOD1-mutant patients. Fig. S1. Demographic and clinical features of patients carrying SOD1 mutations by exons. Fig. S2. Sex and survival. Fig. S3. Prognostic factors and survival.

Additional file 2. Supplementary Methods.

\section{Acknowledgements}

The authors thank the patients for their participation in this study.

\section{Authors' contributions}

L.T., J.D., D.F., and A.L. conceived and designed the study. L.T. and J.D. analyzed data and drafted the manuscript. All authors contributed to the acquisition of data, revising the manuscript and approval of the final version. All authors read and approved the final manuscript.

\section{Funding}

This study was supported by grants from the National Natural Science Foundation of China (81873784, 82071426 and 81901298) and Clinical Cohort Construction Program of Peking University Third Hospital (BYSYDL2019002).

\section{Availability of data and materials}

The datasets used and analyzed during the current study are available from the corresponding author on reasonable request.

\section{Declarations}

Ethics approval and consent to participate

The study was approved by the Ethics Committee of Peking University Third Hospital, Beijing, China and the local medical ethics committees of German MND network.

\section{Consent for publication}

Not applicable.

\section{Competing interests}

The authors declare that they have no competing interests.

\section{Author details}

${ }^{1}$ Department of Neurology, Peking University Third Hospital, Beijing 100191, China. ${ }^{2}$ Beijing Key Laboratory of Biomarker and Translational Research in Neurodegenerative Diseases, Peking University Third Hospital, Beijing 100191, China. ${ }^{3}$ Department of Neurology, Ulm University, 89081 UIm, Germany. ${ }^{4}$ German Center for Neurodegenerative Diseases (DZNE), Ulm Site, 89081 UIm, Germany.

Received: 8 July 2021 Accepted: 13 October 2021

Published online: 28 October 2021

\section{References}

1. Petrov D, Mansfield C, Moussy A, Hermine O. ALS clinical trials review: 20 years of failure. Are we any closer to registering a new treatment? Front Aging Neurosci. 2017;9:68.

2. Abe K, Aoki M, Tsuji S, Itoyama Y, Sobue G, Togo M, et al. Safety and efficacy of edaravone in well defined patients with amyotrophic lateral sclerosis: a randomised, double-blind, placebo-controlled trial. Lancet Neurol. 2017;16(7):505.

3. Zou Z, Zhou Z, Che C, Liu C, He R, Huang H. Genetic epidemiology of amyotrophic lateral sclerosis: a systematic review and meta-analysis. J Neurol Neurosurg Psychiatry. 2017;88(7):540-9.

4. Miller T, Cudkowicz M, Shaw PJ, Andersen PM, Atassi N, Bucelli RC, et al. Phase 1-2 trial of antisense oligonucleotide Tofersen for SOD1 ALS. N Engl J Med. 2020;383(2):109-19.

5. Tang L, Ma Y, Liu X, Chen L, Fan D. Better survival in female SOD1-mutant patients with ALS: a study of SOD1-related natural history. Transl Neurodegener. 2019;8(1):1-10.

6. Dorst J, Chen L, Rosenbohm A, Dreyhaupt J, Hübers A, Schuster J, et al. Prognostic factors in ALS: a comparison between Germany and China. J Neurol. 2019;266(6):1516-25.

7. Bali T, SelfW, Liu J, Siddique T, Wang LH, Bird TD, et al. Defining SOD1 ALS natural history to guide therapeutic clinical trial design. J Neurol Neurosurg Psychiatry. 2017;88(2):99-105.

8. Tang L, Ma Y, Liu X, Chen L, Fan D. Identification of an A4V SOD1 mutation in a Chinese patient with amyotrophic lateral sclerosis without the A4V founder effect common in North America. Amyotroph Lateral Scler Frontotemporal Degener. 2018;19(5-6):466-8.

9. Sabatelli M, Madia F, Conte A, Luigetti M, Zollino M, Mancuso I, et al. Natural history of young-adult amyotrophic lateral sclerosis. Neurology. 2008;71(12):876-81. 